JOURNAL of

MAINE MEDICAL CENTER Journal of Maine Medical Center

\title{
Inclusive Language Matters: Recommendations for Health Care Providers to Address Implicit Bias and Equitable Health Care
}

\author{
Crystal R. Herron \\ Redwood Ink
}

Follow this and additional works at: https://knowledgeconnection.mainehealth.org/jmmc

Part of the Medical Education Commons

\section{Recommended Citation}

Herron, Crystal R. (2021) "Inclusive Language Matters: Recommendations for Health Care Providers to Address Implicit Bias and Equitable Health Care," Journal of Maine Medical Center. Vol. 3 : Iss. 2 , Article 9.

Available at: https://knowledgeconnection.mainehealth.org/jmmc/vol3/iss2/9 https://doi.org/10.46804/ 2641-2225.1093

The views and thoughts expressed in this manuscript belong solely to the author[s] and do not reflect the opinions of the Journal of Maine Medical Center or MaineHealth.

This Application of Best Practices is brought to you for free and open access by Maine Medical Center Department of Medical Education. It has been accepted for inclusion in the Journal of Maine Medical Center by an authorized editor of the MaineHealth Knowledge Connection. For more information, please contact Dina McKelvy mckeld1@mmc.org.

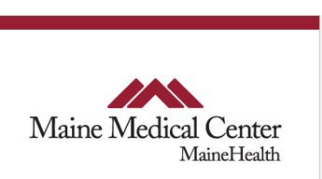


APPLICATION OF BEST PRACTICES

\title{
Inclusive Language Matters: Recommendations for Health Care Providers to Address Implicit Bias and Equitable Health Care
}

\author{
Crystal Herron, PhD, ELS \\ Redwood Ink, Mill Valley, CA
}

Problem Stigmatizing language — written and verbal—can fuel implicit bias among health care professionals, Statement: $\quad$ leading to unintentional negative effects in how they care for patients. To provide equitable care, health care professionals and systems must become aware of the language they use and learn to replace biased language with inclusive language.

Background: The medical field strives to treat all patients equally, yet disparities in health care persist. These disparities are due, in part, to implicit bias that affects how health care professionals and systems care for patients. Although reports recommend developing education programs that address implicit bias, these programs fail to address an important contributor: stigmatizing language used among health care professionals. With guidance, health care professionals and institutions can recognize and replace their biased language to foster more inclusive communication that promotes equitable health care.

Application: The AMA Manual of Style outlines standardized inclusive language that health care professionals can use to address bias in their writing, as well as in their clinical practice, teaching, and research. The guide recommends using person-first language, avoiding generalizations and labeling, describing specific details, and being sensitive to the preferences of individuals or groups. The guide also provides detailed recommendations for using inclusive language regarding race/ethnicity, physical or mental condition, sex or gender, sexual orientation, age, and socioeconomic status. With these guidelines, health care providers can replace stigmatizing language to reduce implicit bias and comprehensively address disparities in health care.

Keywords: $\quad$ bias, stigma, language, health care disparities, health equity

1 mplicit bias is the automatic activation of attitudes or stereotypes that unconsciously and unintentionally affect behaviors and decisions. ${ }^{1}$ In health care, stigmatizing language can propagate implicit bias among health care providers and negatively affect how they care for patients. ${ }^{2-7}$ Although several reports recommend training programs that address implicit bias, ${ }^{8-11}$ these programs do not consider how language used among health care providers in formal and informal settings contributes to bias. Health care providers must develop awareness of their language and learn to replace biased verbal and written language to provide equitable care for patients.

Correspondence: Crystal Herron, PhD, ELS

Redwood Ink

751 E Blithedale Ave, \#1552

Mill Valley, CA 94942

crystal.herron@redwoodink.com

\section{BACKGROUND}

The medical field strives to treat all patients equally, yet disparities in health care persist. The Institute of Medicine (now the National Academy of Medicine) noted that these disparities are due to multiple factors, including "bias, stereotyping, [and] prejudice.... on the part of health care providers."12 Some biases may be explicit, consciously influencing the behaviors of health care providers. ${ }^{1}$ Others occur implicitly, without conscious awareness, creating unintended inequalities in how health care providers treat patients. ${ }^{1,7,13-16}$

Several reports recommend that medical education programs include implicit-bias training that teaches aspiring clinicians about individuating, perspectivetaking, and communicating with patients. ${ }^{8-11}$ However, these programs often overlook an 
important contributor to implicit bias: language that health care providers use to communicate among each other. These communications occur in formal settings, such as reporting, teaching, and presentations (eg, grand rounds). And they also occur in more informal settings, such as chart notes, morning rounds, and discussions between colleagues. Every communication between health care providers creates an opportunity to fuel or thwart implicit bias.

Stigmatizing language-spoken and written-can affect how health care providers view and treat patients. $^{2-6}$ Goddu and colleagues found that stigmatizing language used to describe patients in medical records influenced how medical students and residents treated patients. ${ }^{2}$ Similarly, Kelly and Westerhoff found that stigmatizing language in vignettes led mental health professionals to make character judgments and recommend punitive measures. ${ }^{5}$ These studies support that language used by health care providers can propagate clinician bias and negatively affect patient care.

Some organizations host workshops that train health care professionals on stigmatizing language. Raney and colleagues reported that health care professionals who attended such a workshop planned to reflect on their language and apply what they learned to their practice. However, the participants also identified several barriers to changing stigmatizing language in health care, including cultural norms, normalization of stigmatizing language, and assumptions that colleagues or supervisors would lack interest in the topic. ${ }^{17}$ These barriers suggest that stigmatizing language must be addressed at both an individual and organizational level.

To tackle stigmatizing language among health care providers, individuals and organizations must take initiative to understand, recognize, and replace their biased language. For these efforts, they can seek guidance on inclusive language from the $A M A$ Manual of Style. ${ }^{18}$

\section{APPLICATION}

Since 1962, the American Medical Association has produced the AMA Manual of Style. This guide, published in its $11^{\text {th }}$ edition in 2020 and available online (https://www.amamanualofstyle.com/), 18 has been used globally in academia, industry, government, and publishing. The guide provides a complete description of everything related to medical literature, from grammar to preferred usage to reference formatting. Although the $A M A$ Manual of Style has been designed for publishing, the guide also includes evidence-based, in-depth recommendations that can help health care providers ensure they use inclusive language when communicating with each other in their writing, clinical practice, teaching, and research.

Inclusive language, by definition, avoids certain expressions or words that might exclude particular groups of people. ${ }^{19}$ In this way, inclusive language does not classify a person or persons to a singular identity or categorize them in a specific stereotype. Because these generalizations can propagate bias, the AMA Manual of Style recommends avoiding generalizations and using specific details when describing people. The guide also offers detailed recommendations for avoiding language that imparts bias against persons or groups based on race/ethnicity, physical or mental condition, sex or gender, sexual orientation, age, or socioeconomic status. These recommendations are summarized below, and examples of inclusive versus stigmatizing language in health care can be found in Table 1.

\section{Race and ethnicity}

Although race and ethnicity both refer to cultural constructs, the terms have different meanings. Race refers to a category of humankind that shares certain distinctive physical traits, ${ }^{20}$ whereas ethnicity refers to groups of people classed according to common racial, national, tribal, religious, linguistic, or cultural origin or background. ${ }^{21}$ These terms have some overlap, and they can have biological implications. For example, a person's genetic heritage can influence manifestation of medical conditions. By understanding these nuances, clinicians can better diagnose, treat, and study conditions.

When reporting methods (such as in research and quality improvement initiatives), the AMA Manual of Style recommends explaining how people were classified regarding race, ethnicity, or both. The guide also encourages explaining who defined the designations (eg, predetermined by the researcher or clinician, self-reported by the participant) and why they were assessed. When including an "other" category, be as specific as possible and define who is in that category. 
Specificity is at the core of recommendations by the AMA Manual of Style. When referring to persons indigenous to North America (and their descendants), the guide recommends using the term American Indian and specifying the nation or peoples when possible (eg, Navajo, Iroquoi). This language is more specific than the Native American designation that also includes Hawaiian, Samoan, Guamanian, and Alaskan natives. The guide also outlines differences between the terms Hispanic and Latino. These terms collectively refer to Spanish-speaking people (and their descendants) of Mexico, South and Central America, and the Caribbean. However, the term Latino, in some instances, excludes descendants of people of Mexico or the Caribbean. Similarly, rather than use the broader terms Asian and Asian American, describe Asian persons based on their country or geographic area of origin, such as Chinese, Indian, or Japanese.
The guidelines for referring to persons of color have evolved. Multiracial and people of color are sometimes used when describing the heterogeneous ethnic background of many people. But the AMA Manual of Style generally encourages more specific language that is sensitive to the designations that individuals or groups prefer. For example, in the United States, the term African American may be preferred to Black (although the guide suggests using African American only when referring to US citizens of African descent). Also, language evolves, and preferences may change. In the summer of 2020, the AMA Manual of Style updated its recommendations to capitalize racial/ethnic terms, including Black and White, except when capitalization may be perceived as inappropriate. ${ }^{22}$ Note that these terms should be used in adjectival form (eg, Black patients, White participants) and not in noun form (eg, Blacks, Whites).

Table 1. Examples of Inclusive Alternatives to Stigmatizing Language

\section{Stigmatizing language}

Mr. S is an elderly COVID-19 patient that is diabetic, hypertensive, and suffering from chronic kidney failure.

\section{Inclusive language}

Mr. S is a 72-year-old man with COVID-19 and a history of type II diabetes, hypertension, and chronic kidney failure.
The patient is a Black homosexual woman who lives in a poor community.
The patient is a Black woman who is lesbian and has limited income.
Mr. $\mathrm{M}$ is a 58 -year-old addict who is disabled and confined to a wheelchair.
Mr. $\mathrm{M}$ is a 58-year-old man who uses a wheelchair for a disability and is addicted to opiates.
Miss B is a 34-year-old breast cancer patient who suffers from seizures but is not epileptic.
Miss B is a 34-year-old patient with breast cancer who experiences seizures unrelated to epilepsy.
The man was an Asian stroke victim with a history of alcohol abuse.
The man, who was Chinese, had a stroke and a history of misusing alcohol. 


\section{Diseases, disorders, or disabilities}

A subtle way that bias and stereotype can surface is through labeling -or equating-people with their disabilities or diseases. For example, terms such as diabetic, schizophrenic, and epileptic lump people into a group and should be avoided. Instead, use person-first language, such as "a patient with diabetes." However, person-first language may not always be appropriate. For example, many individuals with autism prefer identify-first language (eg, autistic) or identity-neutral language (eg, on the autism spectrum). ${ }^{23}$ Similar to racial/ethnic designations, consider the preferences of the individual or group being described.

Labeling can also occur in a more subtle form. For example, health care providers may describe patients using their condition in the adjectival form, such as cancer patient or AIDS patient. This phrasing can subtly (ie, unconsciously) reinforce bias and should be avoided. Instead, use patientfirst language, such as "a patient with cancer."

Other subtle forms of labeling include euphemisms and victimization. The AMA Manual of Style recommends avoiding euphemistic descriptors, such as physically challenged, special, or special needs. Instead, use terms such as physically disabled or person with a disability. The guide also recommends avoiding emotional terms that suggest victimization or helplessness, such as afflicted with or suffering from (eg, patient suffering from diabetes). Instead, simply state the condition as a diagnosis (eg, patient with diabetes).

\section{Sex and gender}

The terms sex and gender have distinct meanings. Sex refers to the biological characteristics of males, females, and intersex persons. Gender, on the other hand, is a spectrum and a cultural indicator of a person's personal and social identity. ${ }^{24}$ Based on these definitions, gender should not be used when referring to males and females.

When reporting, the AMA Manual of Style recommends considering the level of specificity needed. In other words, specify sex when it is relevant. Clayton et al suggests that in research, authors should define sex or gender. They also suggest that authors describe the methods used to collect data on sex and gender, and that they note any limitations to those methods. ${ }^{25}$ Also, when reporting participant demographics, include both https://knowledgeconnection.mainehealth.org/jmmc/vol3/iss2/9 sexes in tables and the text, regardless of the ratio. If reporting gender, remember to include all genders as defined in the project.

When sex and gender are not relevant, choose sexneutral terms that avoid bias and are appropriate for the discussion. For example, the terms physician, clinician, nurse, and scientist are sexneutral. However, if comparing males and females (eg, female and male clinicians), then specifying sex is appropriate. The guide also advises not to attempt to change all words to sex-neutral terms. For example, changing manpower to personpower would seem unfamiliar and awkward. Instead, opt for a sex-neutral equivalent, such as workforce or workers.

\section{Personal pronouns}

Although a singular they has been used as a gender-neutral and sex-indefinite singular pronoun since the fourteenth century, the masculine word he has largely served as a generic pronoun. ${ }^{26}$ Over the past few years, several style books have adopted using a singular they, including the 2017 edition of the The Chicago Manual of Style ${ }^{27}$ and the 2019 edition of the Associated Press Stylebook ${ }^{28}$. In 2020, the AMA Manual of Style aligned with these guides in supporting use of they as a singular pronoun. ${ }^{18}$

The AMA Manual of Style recommends using a singular they rather than common-gender pronouns, such as s/he, shem, and shim. If the singular form of they feels awkward or unclear, consider rewording the phrase to use pronouns that are not sex- or gender-specific. For example, "the clinician and their patient" could be replaced with "the clinician and patient." The guide also recommends avoiding sex-specific pronouns unless they are relevant, such as when discussing a patient who selfidentifies as he or she.

\section{Sexual orientation}

The AMA Manual of Style states that sexual orientation should be indicated only when scientifically relevant. The guide also discourages using sexual preference, because the term implies a voluntary choice of sexual orientation, which is not supported by scientific literature. In some cases, health care providers may need to include more specific sexual behaviors, such as men who have sex with men. These details should only be included when relevant. 
The manual also offers guidance on referring to specific groups. For example, the terms lesbians and gay men are preferred over homosexuals, and using gay or gays as a noun is discouraged. Interestingly, the AMA Manual of Style supports using heterosexual, homosexual, bisexual, asexual, and intersexual as adjectives (eg, asexual men). However, this adjectival form could be considered labeling and should be used only when appropriate, such as when preferred by the individual or group.

When discussing couples, the guide encourages using the terms spouse, companion, partner, or life partner. Health care providers may also use samesex couple and same-sex marriage.

\section{Age}

Regarding aging, the AMA Manual of Style recommends avoiding terms that imply a stereotype, such as seniors, elderly, the aged, and aging dependents. Instead, use terms such as older adults, older patients, older individuals, persons 65 years and older, or the older population. Because older is a vague term, the guide recommends using older only to describe people who are 65 years and older. In studies involving humans, researchers should always state specific ages (eg, "older patients aged 65 to 75 years" or "children 18 years and younger").

\section{Socioeconomic status}

The guidance around socioeconomic status mainly focuses on avoiding labeling. The AMA Manual of Style discourages terms such as the poor or the unemployed. Instead, the guide encourages alternative terms, such as low income, no income, limited income, and resource limited.

\section{CONCLUSIONS}

Addressing inclusive language-written and verbal-used among health care providers in formal and informal settings can be a challenging endeavor. And this challenge is compounded by the constant evolution of language and society as designations and preferences change. But with a combination of mindfulness, medical education, continuing education, and mentorship, ,2,7,17,29 health care providers can use inclusive language in all aspects of their career-writing, clinical practice, teaching, and research-to comprehensively address implicit bias and disparities in health care.
Conflict of interest: None

\section{REFERENCES}

1. Devine PG. Stereotypes and prejudice: their automatic and controlled components. J Pers Soc Psychol. 1989;56(1):518. doi:10.1037/0022-3514.56.1.5

2. Goddu AP, O'Conor KJ, Lanzkron S, et al. Do words matter? Stigmatizing language and the transmission of bias in the medical record. J Gen Intern Med. 2018;33(5):685-691. doi:10.1007/s11606-017-4289-2

3. Broyles LM, Binswanger IA, Jenkins JA, et al. Confronting inadvertent stigma and pejorative language in addiction scholarship: a recognition and response. Subst Abuse. 2014;35(3):217-221. doi:10.1080/08897077.2014.930372

4. Samulowitz A, Gremyr I, Eriksson E, Hensing G. "Brave men" and "emotional women": a theory-guided literature review on gender bias in health care and gendered norms towards patients with chronic pain. Pain Res Manag. 2018;2018:6358624. doi:10.1155/2018/6358624

5. Kelly JF, Westerhoff CM. Does it matter how we refer to individuals with substance-related conditions? A randomized study of two commonly used terms. Int J Drug Policy. 2010;21(3):202-207. doi:10.1016/j.drugpo.2009.10.010

6. Shattell MM. Stigmatizing language with unintended meanings: "persons with mental illness" or "mentally ill persons"? Issues Ment Health Nurs. 2009;30(3):199. doi:10.1080/01612840802694668

7. Chapman EN, Kaatz A, Carnes M. Physicians and implicit bias: how doctors may unwittingly perpetuate health care disparities. J Gen Intern Med. 2013;28(11):1504-1510. doi:10.1007/s11606-013-2441-1

8. Dao DK, Goss AL, Hoekzema AS, et al. Integrating theory, content, and method to foster critical consciousness in medical students: a comprehensive model for cultural competence training. Acad Med. 2017;92(3):335-344. doi:10.1097/ACM.0000000000001390

9. Tool for Assessing Cultural Competence Training (TACCT). Association of American Medical Colleges. Accessed April 1, 2021. https://www.aamc.org/what-we-do/diversityinclusion/tool-for-assessing-cultural-competence-training

10. O'Sullivan ED, Schofield SJ. Cognitive bias in clinical medicine. J R Coll Physicians Edinb. 2018;48(3):225-232. doi:10.4997/JRCPE.2018.306

11. Metzl JM, Roberts DE. Structural competency meets structural racism: race, politics, and the structure of medical knowledge. Virtual Mentor. 2014;16(9):674-690. doi:10.1001/virtualmentor.2014.16.9.spec1-1409

12. Nelson A. Unequal treatment: confronting racial and ethnic disparities in health care. J Nat/ Med Assoc. 2002;94(8):666668. Accessed April 1, 2021. https://www.ncbi.nlm.nih.gov/ pmc/articles/PMC2594273/pdf/jnma00325-0024.pdf

13. Green AR, Carney DR, Pallin DJ, et al. Implicit bias among physicians and its prediction of thrombolysis decisions for black and white patients. J Gen Intern Med. 2007;22(9):1231-1238. doi:10.1007/s11606-007-0258-5

14. van Ryn M, Burgess DJ, Dovidio JF, et al. The impact of racism on clinician cognition, behavior, and clinical decision making. Du Bois Rev. 2011;8(1):199-218. doi:10.1017/ S1742058X11000191

15. Quick Safety 23: implicit bias in health care. The Joint Commission. Accessed April 1, 2021. https://www. jointcommission.org/resources/news-and-multimedia/ newsletters/Newsletters/quick-safety/quick-safety-issue23-implicit-bias-in-health-care/implicit-bias-in-health-care 
16. Dovidio JF, Penner LA, Albrecht TL, Norton WE, Gaertner SL, Shelton JN. Disparities and distrust: the implications of psychological processes for understanding racial disparities in health and health care. Soc Sci Med. 2008;67(3):478486. doi:10.1016/j.socscimed.2008.03.019

17. Raney J, Pal R, Lee T, et al. Words matter: an antibias workshop for health care professionals to reduce stigmatizing language. MedEdPORTAL. 2021;17:11115. doi:10.15766/mep_2374-8265.11115

18. Christiansen $\mathrm{S}$, Iverson $\mathrm{C}$, Flanagin $\mathrm{A}$, et al. AMA Manual of Style: A Guide for Authors and Editors. 11th ed. Oxford University Press; 2020.

19. Inclusive language .Dictionary.com. Accessed April 1, 2021. https://www.dictionary.com/browse/inclusive-language

20. Race. Merriam-Webster Dictionary. Accessed April 1, 2021. https://www.merriam-webster.com/dictionary/race

21. Ethnic. Merriam-Webster Dictionary. Accessed April 1, 2021. https://www.merriam-webster.com/dictionary/ethnic

22. Updates to reporting Black and White as racial categories. AMA Style Insider. Published July 1, 2020. Accessed April 1, 2021. https://amastyleinsider.com/2020/07/01/updatesto-reporting-black-and-white-as-racial-categories/
23. Kenny L, Hattersley C, Molins B, Buckley C, Povey C, Pellicano E. Which terms should be used to describe autism? Perspectives from the UK autism community. Autism. 2016;20(4):442-462. doi:10.1177/1362361315588200

24. Gender and health. World Health Organization. Accessed April 1, 2021. https://www.who.int/health-topics/ gender\#tab=tab 1

25. Clayton JA, Tannenbaum C. Reporting sex, gender, or both in clinical research? JAMA. 2016;316(18):1863-1864. doi:10.1001/jama.2016.16405

26. LaScotte DK. Singular they: an empirical study of generic pronoun use. Am Speech. 2016;91(1):62-80. doi:10.1215/00031283-3509469

27. The Chicago Manual of Style: The Essential Guide for Writers, Editors, and Publishers. 17th ed. University of Chicago Press; 2017.

28. The Associated Press Stylebook 2019. Associated Press; 2019.

29. Amutah C, Greenidge K, Mante A, et al. Misrepresenting race - the role of medical schools in propagating physician bias. N Engl J Med. 2021;384(9):872-878. doi:10.1056/ NEJMms2025768 